\title{
Structural and optical properties of nanostructured bismuth oxide
}

\author{
Reem Sami Ali \\ College of Science, Al-Mustanisriyah University, Baghdad, Iraq \\ E-mail address: reem1deema1@yahoo.com
}

\begin{abstract}
Thin films of bismuth oxide have been prepared utilizing vacuum evaporation. XRD anyalysis reveal that all the films were tetragonal polycrystalline structure with a preferred orientation along (002) plane. SEM images indicate that the grain size fall in the category of nanosize. AFM results assure that the nanonstructure behavior of thin films. Optical studies show that these films have a direct transition with optical energy gap equal to $2.5 \mathrm{eV}$.
\end{abstract}

Keywords: thin films' bismuth oxide; optical properties; structural properties

\section{INTRODUCTION}

In recent years, increasing attention has been focused on bismuth oxide, which is one of the most important metal oxide semiconductor has large uses in many fields such as gas sensors, solid oxide fuel cells, optical coatings, metal-insulator-semiconductor (MIS) capacitor, microwave-integrated circuits, ceramics and catalysts, Also used in the manufacture of optical fiber, where he witnessed this area significant progress due to the production of a variety of high-quality optical fibers such as bismuth oxide fiber doped with erbium (Er) and highly nonlinear bismuth oxide fibers [1-3]. These applications because owning a bismuth oxide some characteristics as energy band gap of 2 to $3.96 \mathrm{ev}$, high refractive index of 2.3 at $633 \mathrm{~nm}$, dielectric permittivity, high photoconductivity and significant photoluminescence. $[4,5]$.

Five polymorphs of $\mathrm{Bi}_{2} \mathrm{O}_{3}$, known as $\alpha-, \beta-, \gamma-, \delta$ - and $\omega-\mathrm{Bi}_{2} \mathrm{O}_{3}$ were reported, each one possesses different crystal structures and various electrical, optical and mechanical properties, $\beta$-phase (tetragonal) is n-type semiconductor with a band gap of $2.58 \mathrm{eV}$, and also the metastable phase that can be stabilized to exist at room temperature by doping with impurities such as niobium or tantalum. [6-9].

There are different techniques for the preparation of bismuth oxide films, including: chemical bath deposition (CBD) [10], chemical spray pyrolysis [11], sol-gel [12], reactive magnetron sputtering [13], thermal oxidation of vacuum evaporated bismuth films [14], etc.

The aim of the present work was to study and discuss the structural, surface morphological and optical properties of $\mathrm{Bi}_{2} \mathrm{O}_{3}$ thin films prepared by thermal oxidation of bismuth films in air. 


\section{EXPERIMENTAL}

The vacuum evaporation system at low pressure (about $10^{-5}$ Torr) was used to evaporate the bismuth (purity $99.999 \%$ ) onto cleaned glass substrates, maintained at room temperature. Bismuth oxide has been prepared by thermal oxidation in air at a temperature of $130{ }^{\circ} \mathrm{C}$ for 10 minutes. The thickness of the obtained films was about $200 \mathrm{~nm}$ which calculated by the weight method.

The structural analysis by X-ray diffraction (XRD) was carried out on a Philips type PW 1050 diffractometer using $\mathrm{Cu}-\mathrm{K} \alpha$ radiation with a wavelength of $1.5406 \AA$. Surface morphology was examined using scanning electron microscope (SEM) type (VEGA I I SBH MS 12, operating voltage is $16.00 \mathrm{kv}$ ) and atomic force microscope (AFM) type (SPM, AA3000, Angstrom Advanced Inc. USA).

The transmission and absorption spectra of $\mathrm{Bi}_{2} \mathrm{O}_{3}$ thin film was measured using UVVIS spectrophotometer type (1650-1700, Shimadzu, Japan) in the wavelength range (400$900 \mathrm{~nm})$.

\section{RESULTS AND DISCUSSION}

Figure 1 shows $\mathrm{X}$-ray diffraction (XRD) spectrum of $\mathrm{Bi}_{2} \mathrm{O}_{3}$ thin film, it is clear that the film is polycrystalline in nature . the pattern can be indexed as a tetragonal $\beta-\mathrm{Bi}_{2} \mathrm{O}_{3}$ structure with lattice parameters of $\mathrm{a}=7.742 \AA, \mathrm{c}=5.631 \AA$, $\mathrm{Z}=4$ (JCPDS card no. 27-0050) and a space group $P \overline{4} 21 C$ (114). These results are in good agreement with published results $[15,16]$. The observed and standard 'd' values along with their relative intensities are listed in Table 1. The careful observation of this table shows that the obtained film consists of a Single phase. The maximum intensity peak of $\mathrm{Bi}_{2} \mathrm{O}_{3}$ is observed corresponding to diffraction angle $31.7555^{\circ}$.

The average grain size is about $48.64 \mathrm{~nm}$ for the thin film as estimating from Scherrer equation.

Table 1. Comparison of observed and standard (JCPDS) ' $d$ ' values for $\mathrm{Bi}_{2} \mathrm{O}_{3}$ thin film.

\begin{tabular}{|c|c|c|c|c|}
\hline $\begin{array}{c}\mathbf{d}(\mathbf{A}) \\
\text { observed }\end{array}$ & $\begin{array}{c}\mathbf{d}(\mathbf{\AA}) \\
\text { standard }\end{array}$ & $\mathbf{I} / \mathbf{I 1}$ & ( hkl ) & Type \\
\hline 3.18108 & 3.19 & 81 & 201 & $\beta-\mathrm{Bi}_{2} \mathrm{O}_{3}$ \\
2.93050 & 2.949 & 21 & 211 & $\beta-\mathrm{Bi}_{2} \mathrm{O}_{3}$ \\
2.81557 & 2.815 & 100 & 002 & $\beta-\mathrm{Bi}_{2} \mathrm{O}_{3}$ \\
\hline
\end{tabular}

Figure 2 shows magnification $1.00 \mathrm{kx}$ (a) and $2.00 \mathrm{kx}$ (b) SEM images of $\mathrm{Bi}_{2} \mathrm{O}_{3}$ thin film. From this images The film surface consists of a uniform distribution of nanostructured grains with an average grain size is about $78 \mathrm{~nm}$. 


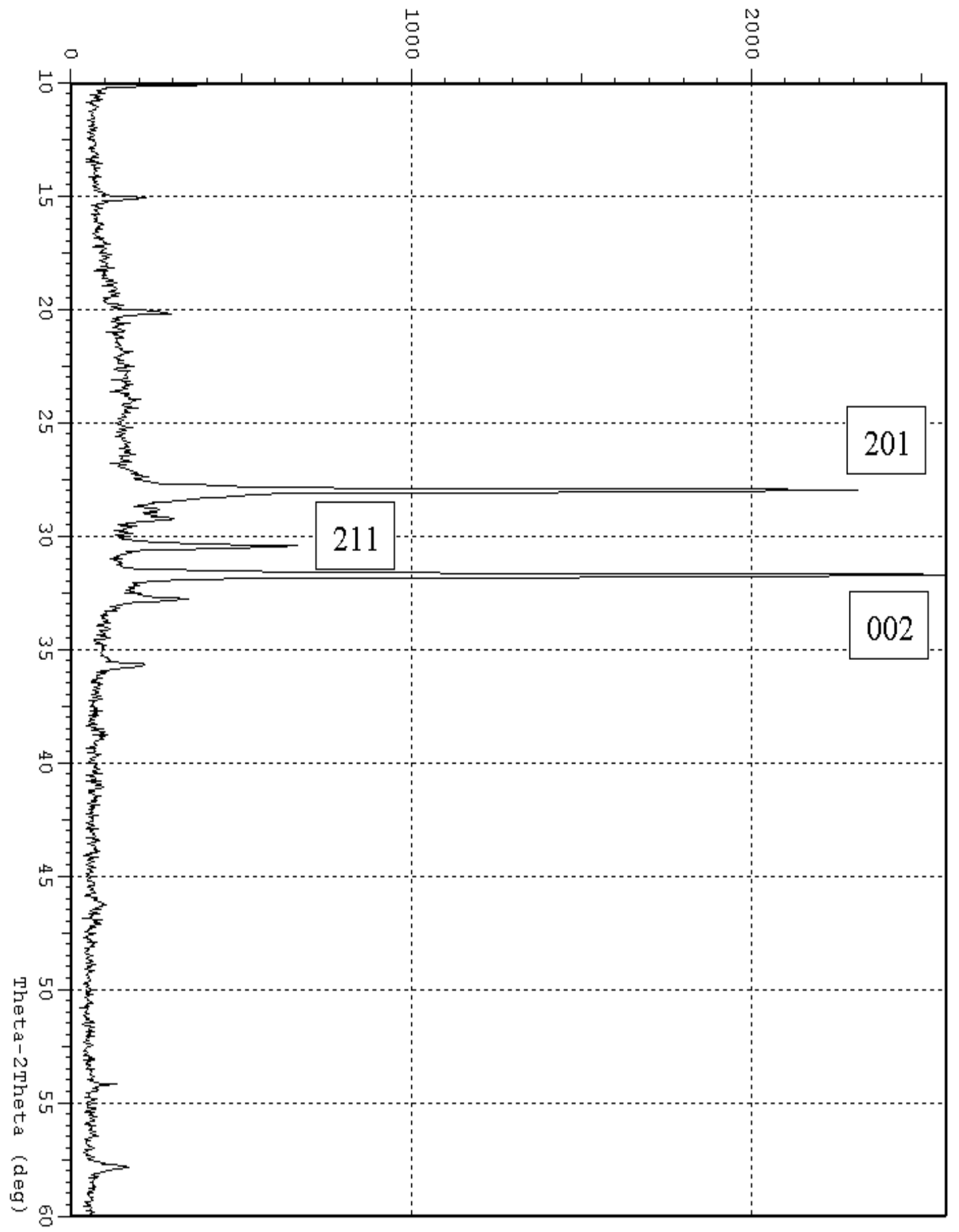

Fig. 1. XRD pattern of grown $\mathrm{Bi}_{2} \mathrm{O}_{3}$ film. 


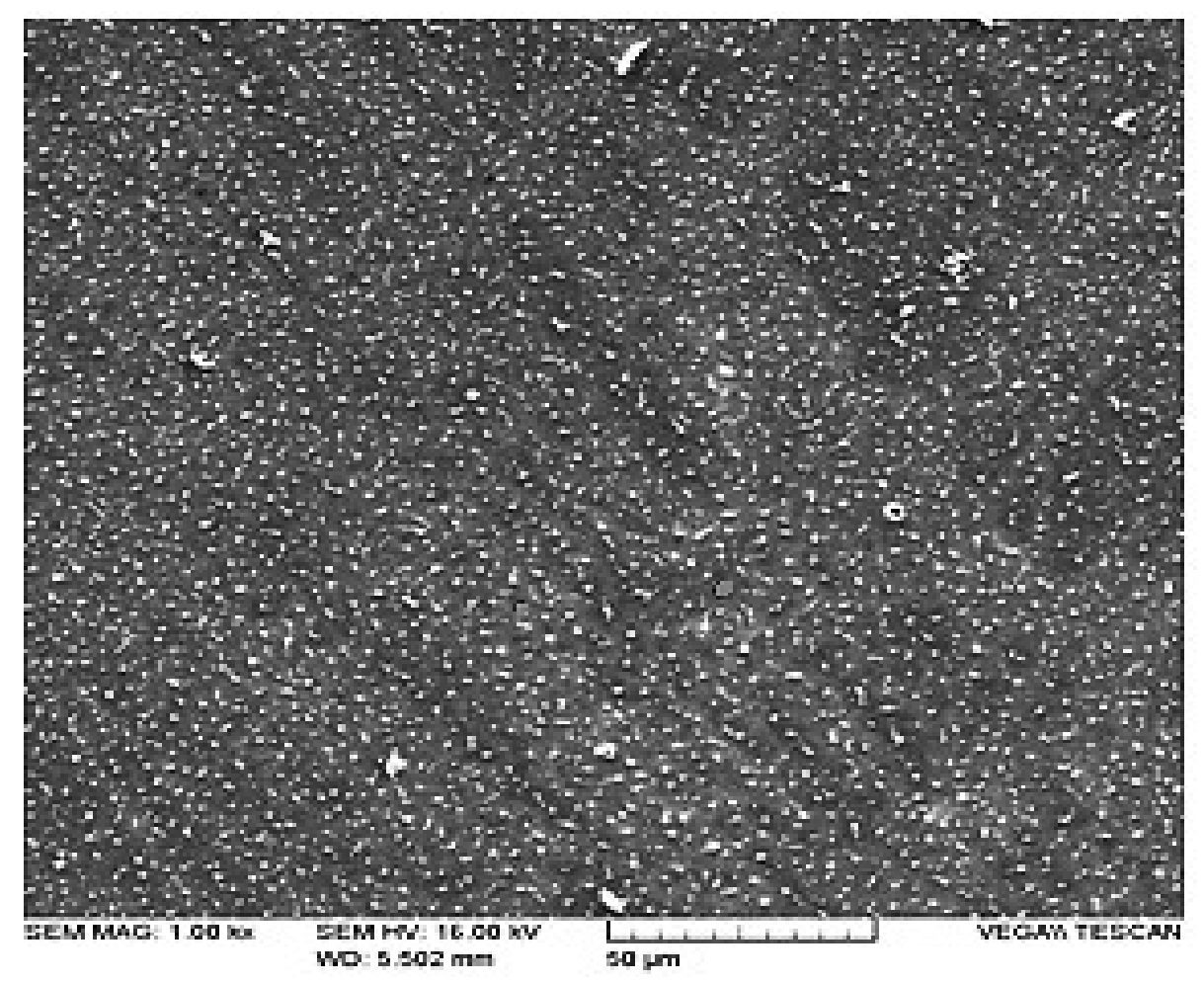

(a)

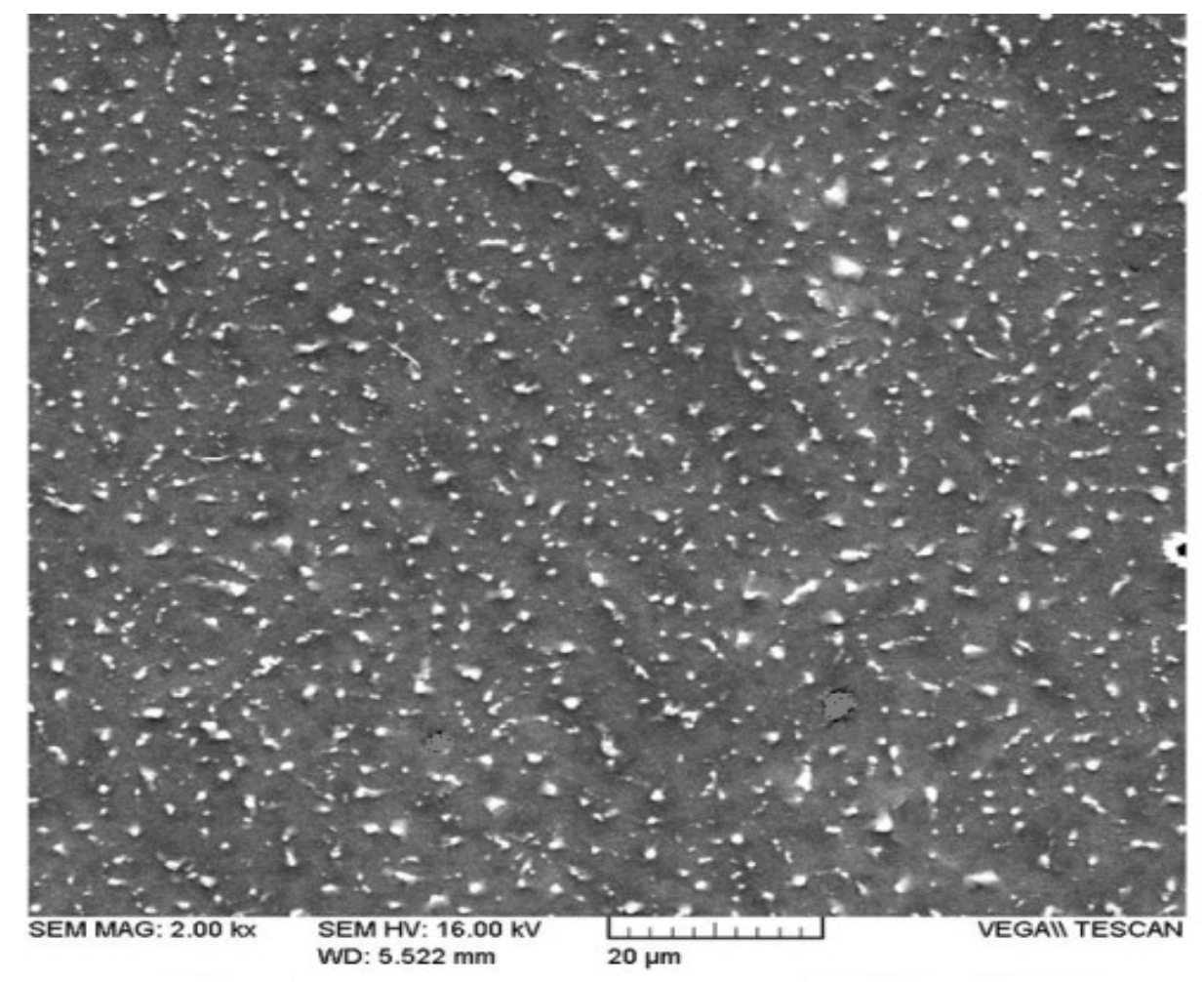

(b)

Fig. 2. MAG1.00 kx (a) and $2.00 \mathrm{kx}$ (b) SEM images of $\mathrm{Bi}_{2} \mathrm{O}_{3}$ film. 
Figure. 3 reveals the two-dimensional (a) and three dimensional (b) AFM images of $\mathrm{Bi}_{2} \mathrm{O}_{3}$ thin film. From this image, the average surface roughness and root mean square roughness values are $0.962 \mathrm{~nm}$ and $1.21 \mathrm{~nm}$ respectively, which indicated the smooth surface morphology of $\mathrm{Bi}_{2} \mathrm{O}_{3}$. The average grain size deduced from AFM is about $81.57 \mathrm{~nm}$ was close to that estimated from SEM. Which indicate that the preparing films have a nanostructure.

The transmittance spectrum of bismuth oxide films deposited onto glass substrates are presented in Figure 4. One can see that the film shows good uniformity and transparency approximately (70-80\%) in the visible and NIR regions, and this high transmittance because there is no free electron (i.e. Electrons are linked to atoms by covalent bonds), this is because the breaking of electron linkage and moving it to the conduction band need photon with high energy [17].

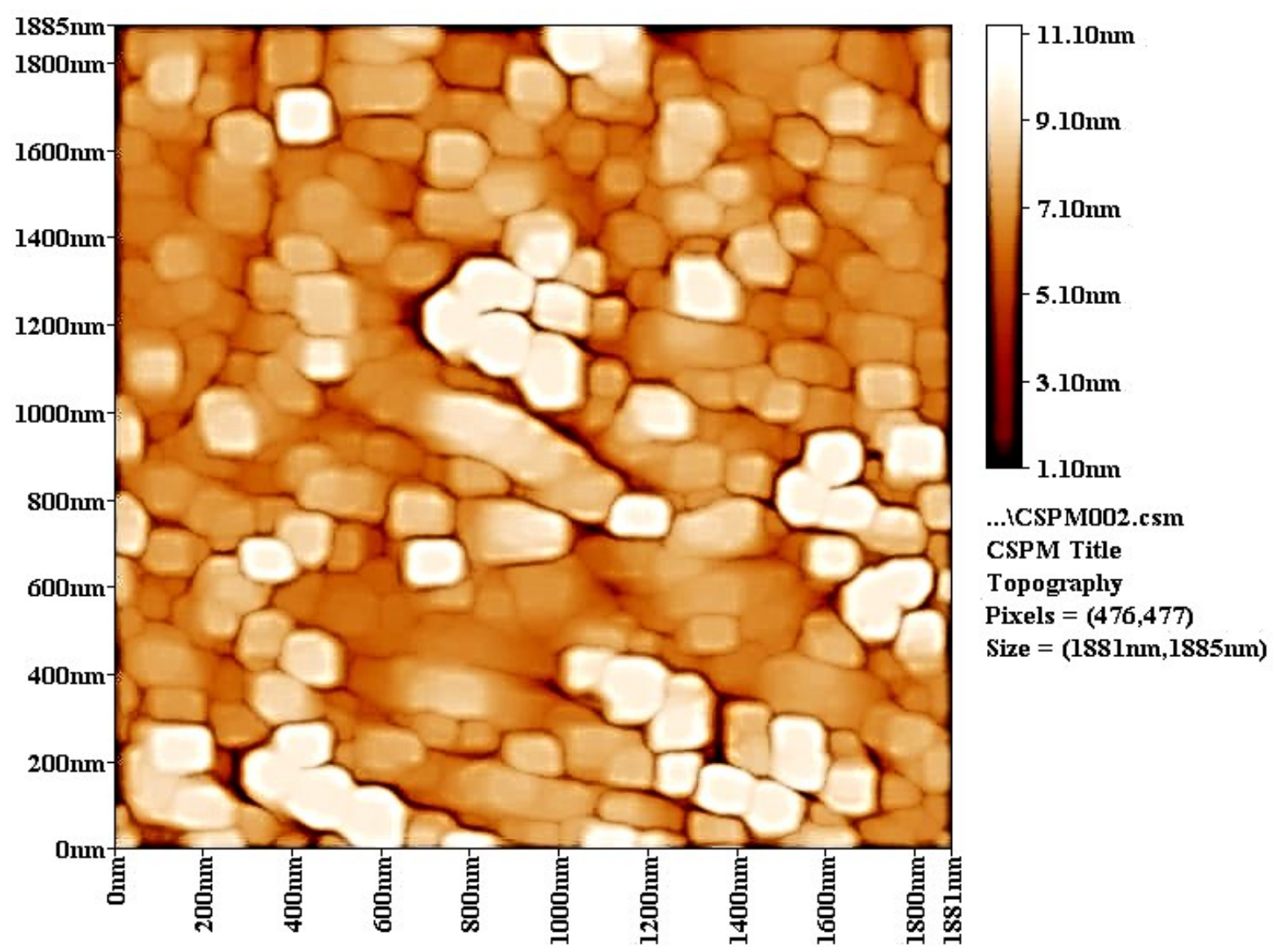

(a)

Fig. 3. Two-dimensional (a) and three-dimensional (b) AFM images of $\mathrm{Bi}_{2} \mathrm{O}_{3}$ film. 


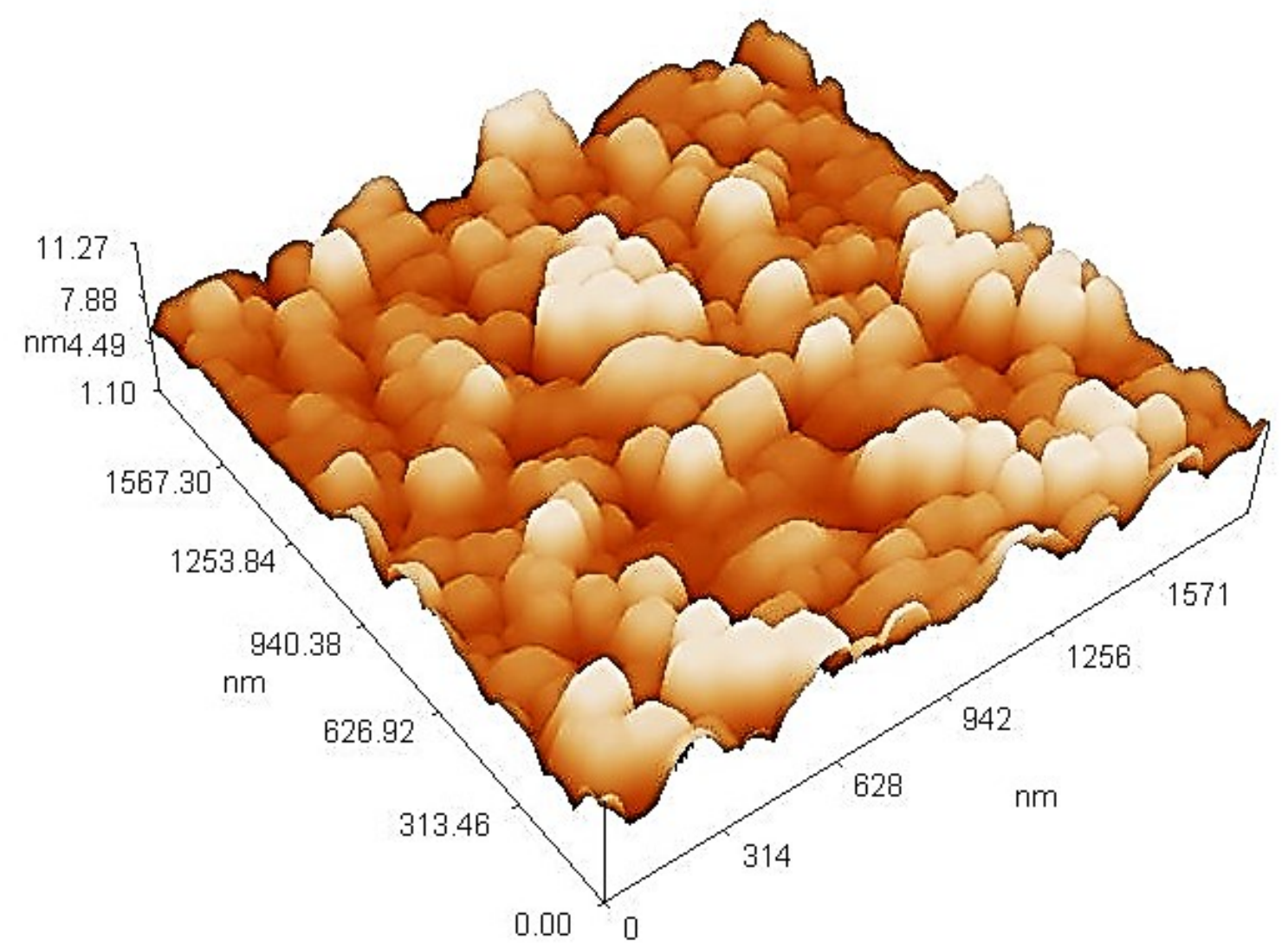

(b)

Fig. 3(continue). Two-dimensional (a) and three-dimensional (b) AFM images of $\mathrm{Bi}_{2} \mathrm{O}_{3}$ film.

Figure 5 shows the optical absorption spectrum of bismuth oxide films, it can be seen that absorption is low at high wavelengths (low energies) and then begins to increase with short wavelength (high energy), where the possibility of electron transitions be significant because of the incident photon energy be enough to move the electron from the valence band to the conduction band, the values of the absorption coefficient helps to conclude the nature of electronic transitions, according to the results in this figure, the coefficient of absorption for the $\mathrm{Bi}_{2} \mathrm{O}_{3}$ thin films is greater than $10^{4} \mathrm{~cm}^{-1}$, this explains that the electron transition is direct, the energy and moment are maintained by the electrons and photons $[17,18]$.

Figure 6 shows the plot of $(\alpha h v)^{2}$ versus hv, where $\alpha$ is the optical absorption coefficient and hv is the energy of the incident photon. The energy gap (Eg) was estimated for a direct transition between valence and conduction bands from the expression [19]:

$$
(\alpha h v)=K(h v-E g)^{1 / 2}
$$




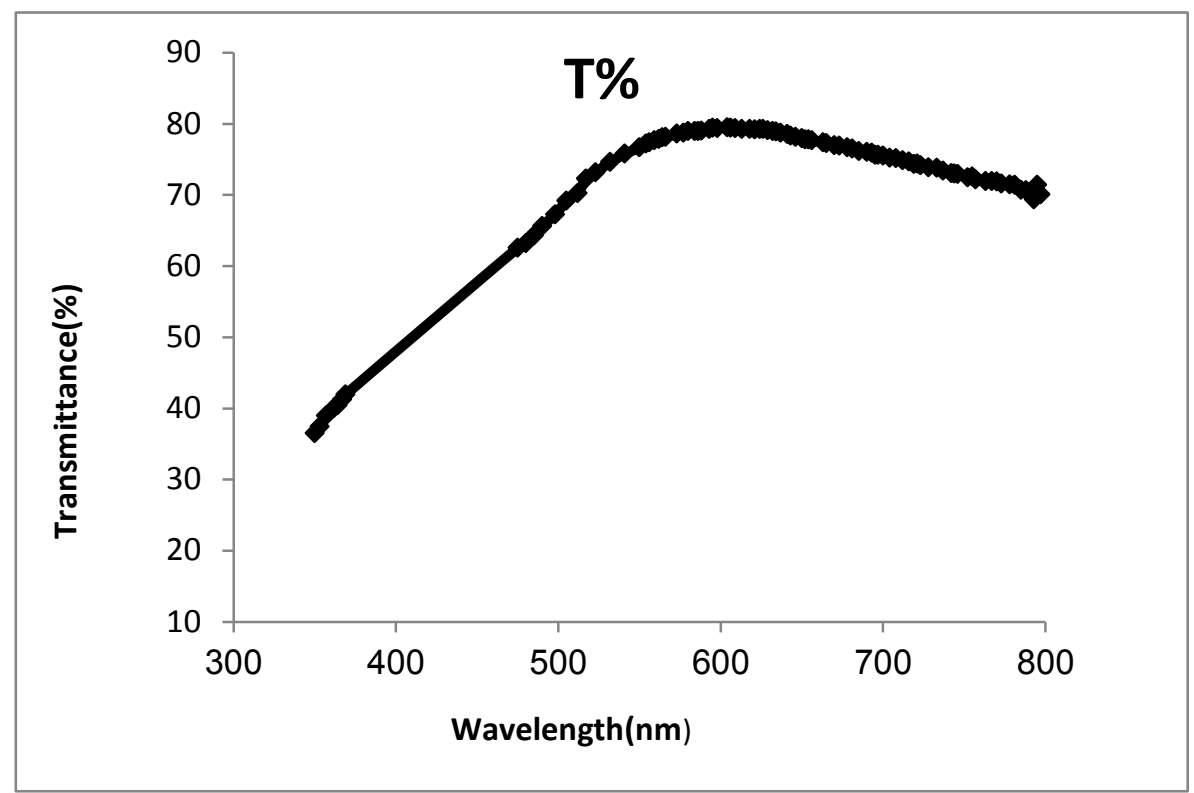

Fig. 4. Transmittance spectrum of $\mathrm{Bi}_{2} \mathrm{O}_{3}$ film.

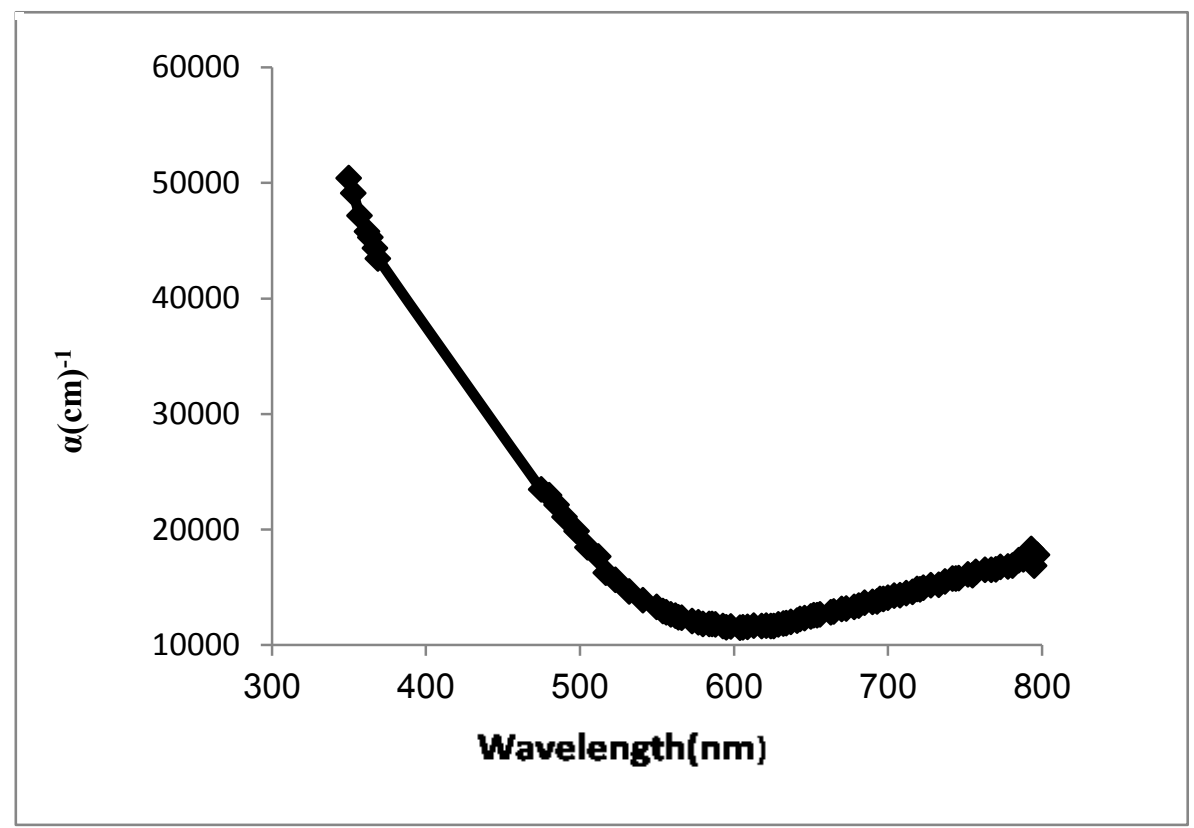

Fig. 5. Absorption spectrum of $\mathrm{Bi}_{2} \mathrm{O}_{3}$ film.

where $\mathrm{K}$ is a parameter, Eg is determined by extrapolating the straight line portion of the spectrum to $\alpha=0$. From this drawing, the optical energy gap $\mathrm{Eg}=2.5 \mathrm{eV}$ is deduced and this value is close to the previously reported value [20,21]. One can notice that This energy gap is rather large for a photovoltaic cell, but should be ideal for photocatalytic water splitting [15]. 


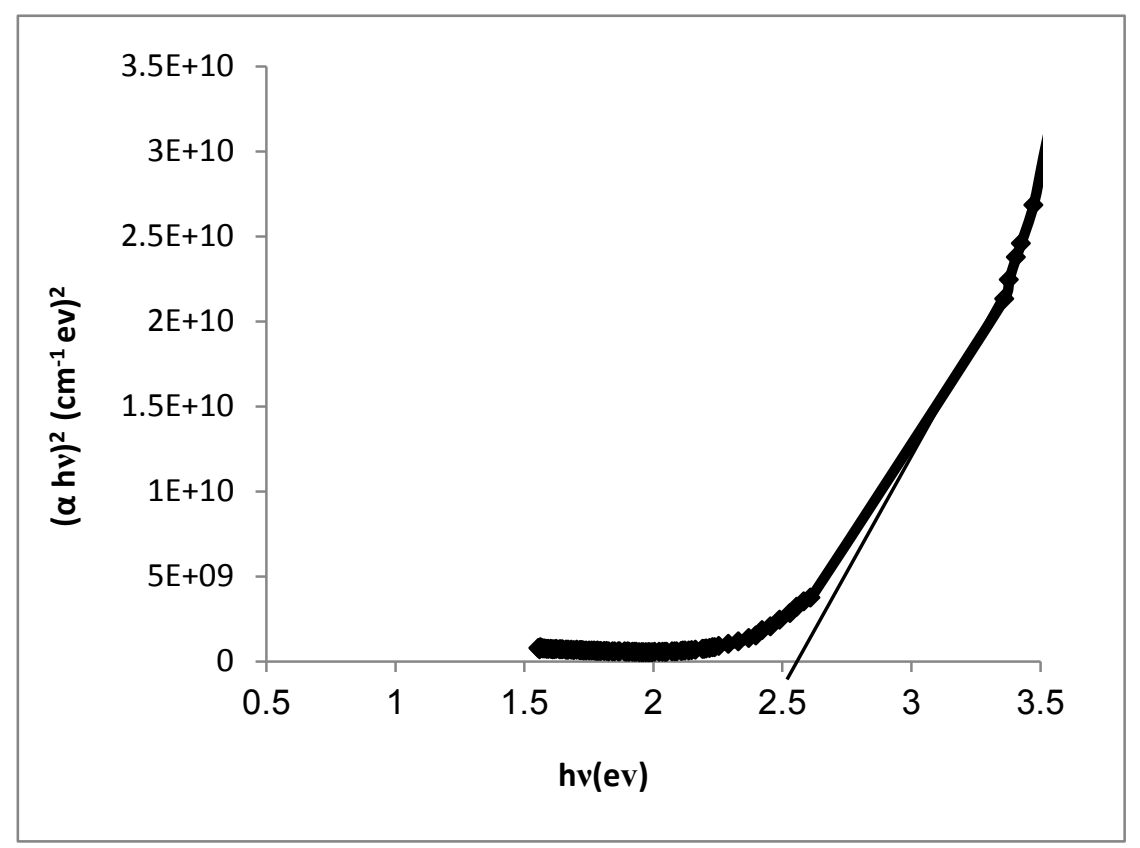

Fig. 6. Plots of $(\alpha h v)^{2}$ versus $h v$ of $\mathrm{Bi}_{2} \mathrm{O}_{3}$ film.

\section{CONCLUSIONS}

Bismuth oxide was prepared successfully by the vacuum evaporation technique. The XRD analysis indicates that all the films were polycrystalline in nature. SEM images were homogenous showing a nanocrystalline structure which agrees with the AFM results which found that the average grain size was about $81.57 \mathrm{~nm}$. the optical measurements shows a direct transition with an optical band gap of $2.5 \mathrm{eV}$.

\section{References}

[1] E. Öztürk, N. O. Kalaycioglu, S. Dayan, H. Ozlu, Bull. Mater. Sci. 36 (2013) 491-494.

[2] S. W. Kang, S. W. Rhee, Thin Solid Films 468 (2004) 79-83.

[3] C. M. Bedoya, M. J. Pinzón, J. E. Alfonso, E. R. Parra, J. J. Olaya, Dyna 79 (2012) 139-148.

[4] J. In, I. Yoon, K. Seo, J. Park, J. Choo, Y. Lee, B. Kim, Chem. Eur. J. 17 (2011) 1304-1309.

[5] S. Condurache-Bota, G. I. Rusu, N. Ţigău, R. Draşovean, C. Gheorghieş, Rev. Roum. Chim. 54 (2009) 205-211.

[6] H. T. Fan, S. S. Pan, X. M. Teng, C. Ye, G. H. Li, L. D. Zhang, Thin Solid Films 513 (2006) 142-147.

[7] S. Park, S. An, H. Ko, C. Jin, and C. Lee, Bull. Korean Chem. Soc. 33 (2012) 3368-3372.

[8] L. Leontie, M. Caraman, M. Alexe, C. Harnagea, Surf Sci 507-510 (2002) 480-485. 
[9] A. J. Salazar-Pérez, M. A. Camacho-López, R. A. Morales-Luckie, V. Sánchez-Mendieta, F. Ureña-Núñez, J. Arenas-Alatorre, Superficies y Vacio 18 (2005) 4-8.

[10] T. P. Gujar, V. R. Shinde, C. D. Lokhande, R. S. Mane, S. -H. Han, Appl Surf Sci 250 (2005) 161-167.

[11] V. V. Killedar, C. H. Bhosale, C. D. Lokhande, Tr. J. Phys 22 (1998) 825-830.

[12] M. Gotić, S. Popović, S. Musić, Mater Lett 61 (2007) 709-714.

[13] P. Lunca Popa, S. Sønderby, S. Kerdsongpanya, J. Lu, N. Bonanos, P. Eklund, J. Appl. Phys. 113 (2013) 046101.

[14] S. Patil, V. Puri, Arch. Appl. Sci. Res. 3 (2011) 14-24.

[15] J. Morasch, S. Li, J. Brötz, W. Jaegermann, A. Klein, Phys. Status Solidi A211 (2014) 93-100.

[16] Gopinath P., Chandiramouli R., Res. J. Pharm. Biol. Chem. Sci. 4 (2013) 8-14.

[17] M. Dahshan," Introduction to Material Science and Engineering", 2nd Ed, (2002).

[18] B. Thangaraju, P. Kalianna, Cryst. Res. Techno 35 (2000).

[19] S. M .Sze, " Physics of Semiconductor Device", 3rd Ed, John Wiley (2007).

[20] Hashim A. R. Zalzala, Basheer Y. Muhson, Muhnad A. Ahmed, Journal of Al-Nahrain University 15 ( 2012) 80-82.

[21] R. A. Ismail, Journal of Semiconductor Technology And Science 6 (2006) 119-123. 